\title{
Budesonide/formoterol combination in COPD: a US perspective
}

This article was published in the following Dove Press journal: International Journal of Chronic Obstructive Pulmonary Disease I October 2010

Number of times this article has been viewed

\author{
Amir Sharafkhaneh ${ }^{1,2}$ \\ Amarbir S Mattewal' \\ Vinu MAbraham' \\ Goutham Dronavalli' \\ Nicola A Hanania' \\ 'Section of Pulmonary, Critical \\ Care Medicine and Sleep Medicine, \\ Department of Medicine, Baylor \\ College of Medicine, Houston, Texas, \\ USA; ${ }^{2}$ Section of Pulmonary, Critical \\ Care Medicine and Sleep Medicine, \\ Medical Care Line, Michael E DeBakey \\ VA Medical Center, Houston, Texas, \\ USA
}

\begin{abstract}
Chronic obstructive pulmonary disease (COPD) is a preventable and treatable disease of the lung caused primarily by exposure to cigarette smoke. Clinically, it presents with progressive cough, sputum production, dyspnea, reduced exercise capacity, and diminished quality of life. Physiologically, it is characterized by the presence of partially reversible expiratory airflow limitation and hyperinflation. Pathologically, COPD is a multicomponent disease characterized by bronchial submucosal mucous gland hypertrophy, bronchiolar mucosal hyperplasia, increased luminal inflammatory mucus, airway wall inflammation and scarring, and alveolar wall damage and destruction. Management of COPD involves both pharmacological and nonpharmacological approaches. Bronchodilators and inhaled corticosteroids are recommended medications for management of COPD especially in more severe disease. Combination therapies containing these medications are now available for the chronic management of stable COPD. The US Food and Drug Administration, recently, approved the combination of budesonide/formoterol (160/4.5 $\mu \mathrm{g}$; Symbicort ${ }^{\mathrm{T} M}$, AstraZeneca, Sweden) delivered via a pressurized meter dose inhaler for maintenance management of stable COPD. The combination also is delivered via dry powder inhaler (Symbicort ${ }^{\mathrm{TM}}$ and Turbuhaler ${ }^{\mathrm{TM}}$, AstraZeneca, Sweden) but is not approved for use in the United States. In this review, we evaluate available data of the efficacy and safety of this combination in patients with COPD.
\end{abstract}

Keywords: inhaled steroid, bronchodilator, $\beta_{2}$-agonist, lung function, quality of life, COPD exacerbations

\section{Introduction}

Chronic obstructive pulmonary disease (COPD) is a debilitating disease that results in significant morbidity and mortality. Patients with COPD present with dyspnea, cough, sputum production, decreased exercise capacity, and fatigue. COPD not only affects the patients physically, but also significantly affects their quality of life. The course of COPD is complicated by episodes of acute exacerbations which are associated with increased mortality, worse quality of life, and faster lung function decline. ${ }^{1}$

COPD is a major public health problem in the United States and throughout the world. Currently, it is estimated that 12.6 million individuals are affected by COPD, and it is the sixth chronic disease condition right after diabetes mellitus and asthma in the United States. Moreover, recent data indicate that as high as $45 \%$ of patients who suffer from COPD are not yet diagnosed. COPD is also a major cause of mortality. Currently, COPD results in about 120,000 deaths in the United States and is the fourth leading cause of death. ${ }^{2}$ Significant preventive efforts in control of hypertension and hypercholesterolemia resulted in reduced relative mortality of
Correspondence: Amir Sharafkhaneh Department of Medicine, Baylor College of Medicine, 2002 Holcombe Blvd., Houston, TX 77030, USA

Tel $+\mid$ 7I3-794-73I8

Fax + $713-794-7316$

Emailamirs@bcm.tmc.edu 
cardiovascular diseases, whereas the mortality due to COPD has been on the rise. ${ }^{3}$ An estimation of $\$ 42.6$ billion dollars are spent on COPD in the United States. The majority of these costs are related to exacerbations resulting from this disease. $^{4}$

Physiologically, COPD is characterized by expiratory airflow limitation that is partially reversible. ${ }^{5}$ This airflow limitation results in hyperinflation which causes progressive dyspnea and exercise limitation. This results in a decline in physical activity causing worsening of respiratory status due to deconditioning. ${ }^{6}$ Pathologically, COPD is characterized by emphysema, small airway wall thickening, mucous metaplasia, occlusion of small airways with inflammatory mucus, and mucous gland hypertrophy and hyperplasia in large airways. ${ }^{7-9}$ Various inflammatory cells including macrophages, neutrophils, and CD8 T lymphocytes are increased in lungs of patients with COPD. ${ }^{7}$

Current management guidelines consider COPD as a "preventable and treatable" disease. ${ }^{5}$ The American Thoracic Society/European Respiratory Society outlines clear goals for the management of patients with COPD. ${ }^{5}$ Treatment goals include the need to improve symptoms, exercise capacity, and quality of life and reduce complications including exacerbations, hospitalizations, and mortality. Smoking cessation clearly slows down lung function decline and prolongs life in COPD, whereas other preventive measures including influenza and pneumococcal vaccinations may affect various outcomes positively in patients with COPD. Long-term oxygen therapy in COPD patients with resting hypoxemia also reduces mortality, ${ }^{5,10}$ Although current pharmacological interventions can improve symptoms, quality of life, and exercise tolerance, none have been shown to alter the natural history of this disease by reducing the decline in lung function or reducing mortality.

Bronchodilators are the main stay of therapy for symptomatic COPD. Inhaled long-acting agents are in the forefront of COPD pharmacotherapy. ${ }^{5}$ In contrast, the role of inhaled corticosteroids (ICSs) in COPD is more controversial. Current guidelines recommend use of ICS in COPD patients with severe disease and in those with history of exacerbations. In the past few years, the US Food and Drug Administration (FDA) approved combination therapies of long-acting $\beta_{2}$-agonist (LABA) and ICS. One of the available combinations includes formoterol (LABA) and budesonide (ICS; BFC) (Symbicort ${ }^{\mathrm{TM}}$, AstraZeneca, Sweden) administered in a metered dose inhaler twice daily for patients with stable COPD. The efficacy and safety data of this combination in patients with COPD are reviewed.

\section{Pharmacology}

\section{Formoterol}

Formoterol is a LABA which is currently approved for the twice-daily maintenance therapy of COPD. The pharmacologic effects of $\beta_{2}$-agonists, including formoterol are at least partly attributable to their ability to activate intracellular adenylyl cyclase, which stimulates the conversion of adenosine triphosphate to cyclic adenosine monophosphate (cAMP) in bronchial smooth muscle cells. ${ }^{11}$ Increased cAMP causes relaxation of the smooth muscle and results in bronchodilatation. The bronchodilator response to a given $\beta_{2}$-agonist is determined by the amount of the drug in the vicinity of the $\beta_{2}$-adrenergic receptor, the degree of which depends on the lipophilicity and chemical structure of the drug. ${ }^{12}$ The intrinsic efficacy of a $\beta_{2}$-agonist has also an important role in determining the clinical response to these agents. ${ }^{13}$

Formoterol, unlike other bronchodilators, has physiochemical properties that provide a rapid onset and long duration of action. The lipophilicity of formoterol, like salmeterol, allows it to penetrate and be stored in smooth-muscle cell membranes, resulting in a long duration of bronchodilatory action. Formoterol also has hydrophilic properties like albuterol, which enables it to access and activate the $\beta_{2}$-receptor rapidly and exert a rapid onset of action. ${ }^{14}$ Furthermore, in contrast to other existing $\beta_{2}$-agonists, formoterol has a very high intrinsic efficacy at the $\beta_{2}$-receptor.

Formoterol has plasma protein binding of approximately $60 \%$ in in vitro studies and is metabolized primarily through direct glucuronidation. ${ }^{15}$ In healthy volunteers who received high-dose formoterol via the Aerolizer ${ }^{\circledR}$ device, $C_{\max }$ of formoterol was observed within 5 minutes of dosing in the majority of subjects, indicating that formoterol is rapidly absorbed from the large and small airways after inhalation. Some subjects had additional increase in plasma levels between 3 hours and 6 hours postdose, possibly due to enterohepatic recirculation of the drug. The mean terminal half-life was 10 hours. ${ }^{16}$

\section{Budesonide}

Budesonide is an anti-inflammatory synthetic ICS. It is a nonhalogenated corticosteroid that exhibits potent glucocorticoid activity and weak mineralocorticoid activity. Budesonide is provided as the mixture of 2 epimers (22R and $22 \mathrm{~S}$ ). Corticosteroid actions in the human body are mediated by the glucocorticoid receptor (GR). This receptor is found in the cytoplasm of most cell types. ${ }^{17}$ Corticosteroids like budesonide have a wide range of inhibitory activities against many cell types, including lymphocytes, eosinophils, mast 
cells, neutrophils, and macrophages. It is also active against mediators involved in allergic-mediated inflammation and nonallergic-mediated inflammation, such as cytokines, histamine, and leukotrienes. ${ }^{18}$ In vitro evidence suggests that budesonide may phenotypically alter alveolar macrophages and reduce histamine release from basophils. It also seems to inhibit monocyte-mediated cytotoxicity and eosinophil activation.

Budesonide has a high topical potency and a low systemic bioavailability. The relative affinity of budesonide for the GR is higher compared with previously developed inhaled steroids. ${ }^{18}$ In standard in vitro tests and animal models, budesonide was found to have an approximately 200-fold higher affinity for the GR and a 1,000-fold higher topical anti-inflammatory potency than cortisol. Inhaled budesonide is a good medium of drug delivery as the compound is a moderately lipophilic agent with rapid uptake into airway mucosa. ${ }^{18}$

Tests performed showed that after oral administration of budesonide in healthy adults, the peak plasma concentration was reached within approximately 1-2 hours. Budesonide deposited in the oropharynx at the time of inhalation is assumed to be swallowed and eventually absorbed from the gastrointestinal tract. However, because of extensive first-pass elimination of oral budesonide (approximately $85 \%-90 \%$ ), very little drug is systemically absorbed. In vitro studies with human liver homogenates indicate that budesonide is rapidly and extensively metabolized by the cytochrome P450 system. ${ }^{18}$ The resulting major metabolites of budesonide are $16 \alpha$-hydroxyprednisolone and $6 \beta$-hydroxybudesonide. These metabolites have GR activity which is only $1 \%$ or less than that of the parent drug and are hence not potent.

Budesonide has a high affinity for the lung increasing its usefulness as an inhaled medication. A study that used the isolated perfused rat lung model demonstrated that a substantial fraction of budesonide present in the lungs is bound to tissue components and is retained for an extended time period. ${ }^{19}$ It seems that budesonide fatty acid conjugates are formed and retained in the lung on inhalation.

Budesonide is primarily excreted as metabolites in the urine and feces. The renal elimination of unchanged budesonide is low because of its extensive biotransformation in the liver. The terminal elimination half-life of budesonide after inhalation is approximately 2.3 hours in children 3-6 years of age with asthma. ${ }^{18}$

Overall, the pharmacokinetic profile of inhaled budesonide allows for a long duration of local therapeutic effects in the lungs with minimal systemic exposure.

\section{Combination of budesonide and formoterol}

The combination of ICS with LABA has been used extensively in asthma but only recently in COPD. Many questions regarding the use of such combination therapy in COPD remain to be answered: Does this combination have additional benefits than either drug used alone? Does one class modify the actions of the other? Do they have any synergistic action?

\section{ICS effects on LABA}

Much of the information about the interactions between ICS and LABA come from the animal models. When rats were administered salmeterol systemically for as little as 1 week, down regulation of pulmonary $\beta_{2}$-receptors density, as much as $70 \%$, and desensitization of $\beta$ receptors activity were observed. ${ }^{20}$ However, the addition of corticosteroids attenuated this effect. ${ }^{20}$ Dexamethasone increased the number and rate of synthesis of $\beta_{2}$-receptors in human lung tissue by increasing the transcription of $\beta$ receptor gene. ${ }^{21}$ Similar results were found when hamster smooth muscle cells were treated with triamcinolone acetonide. ${ }^{22}$

Furthermore, the addition of corticosteroids to LABA promotes the transcription of $\beta_{2}$-receptor gene leading to the upregulation of $\beta_{2}$-receptor expression. ${ }^{23,24}$ The increase in density or upregulation of $\beta$ receptors was also shown in in vivo patients taking intra nasal steroids. ${ }^{25}$ Apart from decreased density of $\beta_{2}$-receptors seen with the regular use of LABA, inflammatory states are associated with uncoupling of $\beta_{2}$-receptors leading to decreased efficacy of $\beta$-agonists. Corticosteroids can reverse this effect; an effect thought to be mediated through decreased expression of G-receptor kinase $2 .^{26}$

\section{LABA effects on ICS}

In primary human lung fibroblasts and vascular smooth muscle cells, salbutamol and salmeterol promoted the translocation of cytosolic GRs into the nucleus as early as 30 minutes after treatment of cells and completed within 4 hours. ${ }^{27}$ This activity was similar but less robust compared with application of dexamethasone or fluticasone. The BFC activated the GR faster than each drug alone when they were applied to human bronchial smooth muscle cells. ${ }^{28}$ Also, there appeared to be a synergistic effect of the combination of the drugs in inhibiting the proliferation of human bronchial smooth muscle cells. This mechanism was likely through stimulation of $\mathrm{p} 21$. Interestingly, the effective dosages of budesonide and formoterol when used in combination were much lower than required when used individually. Furthermore, formoterol, when added 
to budesonide in human lung fibroblasts exerted an additive effect on the inhibition of interleukin-1 $\beta$ and stimulated production of granulocyte-macrophage colony stimulating factor, intercellular adhesion molecule, and vascular cell adhesion molecule. ${ }^{29}$ This could clinically translate into decreased influx of inflammatory cells and better disease control.

In summary, the combination of ICS and LABA appears to have multiple beneficial effects, some of which may be synergistic. This combination also allows for lower doses of each drug, thus potentially decreasing the side effects.

\section{Clinical data}

Reducing symptoms is one of the most important goals in management of COPD patients. Although initiation of therapy is based mostly on severity of COPD as defined by forced expiratory volume in 1 second $\left(\mathrm{FEV}_{1}\right)$ and symptoms, advancement of therapy is mostly on the basis of improvement of symptoms. Four large randomized controlled trials evaluated efficacy and safety of BFC compared with budesonide (B), formoterol (F), and placebo (PLB) in patients with moderate-to-severe COPD and history of at least 1 exacerbation within the 1 year prior to screening (Table 1). ${ }^{30-33}$ Table 2 outlines the detail of the 4 pivotal studies.

Demographic and baseline characteristics were very similar among the 4 trials with mean age of about 63 years, mean prebronchodilator $\mathrm{FEV}_{1}$ of about $1-1.1 \mathrm{~L}(36 \%-40 \%$ predicted), and a range of 40-44 pack years of smoking. Further, study participants suffered from other comorbid conditions including hypertension, abnormal lipid profile, cardiac disease, diabetes mellitus, and osteoporosis. As shown in Table 2, all studies included changes in $\mathrm{FEV}_{1}$ from baseline as one of the primary end points, ${ }^{30-33}$ whereas the 2 earlier studies also included COPD exacerbation as a coprimary efficacy outcome variable. ${ }^{30,31}$

The BFC is produced in 2 different delivery devices including the dry powder inhaler (DPI) and pressurized meter dose inhaler (pMDI). Although large clinical trials evaluated efficacy of BFC on both devices, only the pMDI is

Table I Major inclusion criteria in pivotal studies of combination BFC

\begin{tabular}{ll}
\hline Age & $\geq 40 y$ \\
Duration of COPD symptoms & $\geq 2 y$ \\
Smoking history & $\geq 10 y$ \\
Prebronchodilator FEV $1 \%$ ) & $\leq 50 \%$ \\
FEV $/ \mathrm{IVC}$ or FEV,/FVC $_{1}$ & $\geq 70 \%$ \\
Exacerbation (requiring systemic steroid & $\geq 1$ within $2-12$ months \\
and/or antibiotics) & before the study \\
\hline
\end{tabular}

Abbreviations: COPD, chronic obstructive pulmonary disease; FEV , forced expiratory volume in I second; FVC, forced vital capacity; VC, vital capacity. approved by US FDA, whereas the Turbuhaler ${ }^{\mathrm{TM}}$ is approved in Europe. Head-to-head trials comparing the 2 delivery devices in COPD is lacking. However, in a study of adults and adolescents with asthma, BFC pMDI and BFC Turbuhaler significantly ( $P<0.001$ for both) improved AM peak expiratory flow (PEF; the primary efficacy variable) compared with budesonide pMDI. ${ }^{34}$ In a 52-week long-term safety study of patients with asthma $\geq 12$ years of age, BFC pMDI was equally well tolerated and as effective as BFC Turbuhaler in adults and adolescents with asthma. ${ }^{35}$ Thus, although the comparative data in COPD is lacking, asthma data supports effectiveness in both delivery forms.

\section{Efficacy of budesonide/formoterol combination \\ Lung function}

Szafranski et $\mathrm{al}^{30}$ reported improvement with BFC in $\mathrm{FEV}_{1}$ of $15 \%$ compared with PLB $(P<0.001)$, 9\% compared with B $(P<0.001)$, and $1 \%$ compared with $\mathrm{F}(P>0.05)$. Further, the morning and evening PEF increased significantly in BFC arm compared with PLB, B, or F $(P<0.001)$. Calverley et $\mathrm{al}^{31}$ optimized patients with moderate-or-worse COPD with 2 weeks of oral steroid (prednisolone $30 \mathrm{mg}$ daily), formoterol (Oxis $9 \mu \mathrm{g}$ two times a day [bid]) and as needed terbutaline (Bricanyl $0.5 \mathrm{mg}$ ) before randomization to the study arms (BFC, B, F, and PLB). FEV ${ }_{1}$ significantly improved with the optimization $(0.21 \pm 0.32 \mathrm{~L})$. During the subsequent postrandomization study period (12 months), BFC maintained the improvement in $\mathrm{FEV}_{1}$, whereas the other arms (B, F, and PLB) showed significant drop in mean postdose $\mathrm{FEV}_{1}$. The difference in mean postdose $\mathrm{FEV}_{1}$ was significantly higher in BFC arm compared with PLB (14\%), B (11\%), and F (5\%). Similar changes were seen in vital capacity and morning PEF. Evening PEF was also higher in BFC compared with PLB and B. ${ }^{31}$

Tashkin et $\mathrm{al}^{33}$ (6-month study) and Rennard et $\mathrm{al}^{32}$ (12-month study) reported on coprimary end points of predose $\mathrm{FEV}_{1}$ and 1-hour postdose $\mathrm{FEV}_{1}$. In both of these studies conducted in the United States, BFC was administered in a pMDI. In Tashkin's study, BFC (320/9 $\mu \mathrm{g}$ bid) increased predose $\mathrm{FEV}_{1}$ significantly compared with $\mathrm{F}, \mathrm{B}$, and PLB, whereas BFC (160/9 $\mu \mathrm{g}$ bid) only increased predose $\mathrm{FEV}_{1}$ significantly compared with B and PLB but not F. Furthermore,

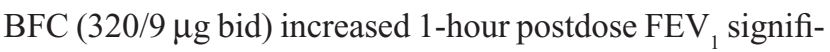
cantly compared with F, B, and PLB, whereas BFC (160/9 $\mu \mathrm{g}$ bid) only increased 1-hour postdose $\mathrm{FEV}_{1}$ significantly compared with $\mathrm{B}$ and PLB but not $\mathrm{F}^{33}$ In Rennard's study, BFC (320/9 $\mu \mathrm{g}$ bid) increased predose and 1-hour postdose 
Table 2 Pivotal randomized controlled trials of BFC

\begin{tabular}{|c|c|c|c|c|c|c|c|c|}
\hline Author & $\mathbf{N}$ & $\begin{array}{l}\text { Duration, } \\
\text { months }\end{array}$ & Age. years & $\begin{array}{l}\text { Baseline } \\
\text { FEV }\end{array}$ & $\begin{array}{l}\text { Smoking history, } \\
\text { pack/year }\end{array}$ & $\begin{array}{l}\text { Treatment, } \mu \mathrm{g} \text { bid } \\
\text { delivered dose }\end{array}$ & $\begin{array}{l}\text { Delivery } \\
\text { system }\end{array}$ & $\begin{array}{l}\text { Primary } \\
\text { end point }\end{array}$ \\
\hline Szafranski et a ${ }^{31}$ & 812 & 12 & 64 & $\begin{array}{l}0.99 \mathrm{~L} \\
(36 \%)\end{array}$ & 44 & $\begin{array}{l}\text { BFC, } 320 / 9 \text { B, } 200 \\
F, 9 \text { PLB }\end{array}$ & Turbuhaler & $\begin{array}{l}\text { Number of severe } \\
A E C O P D \text { Change } \\
\text { in FEV }\end{array}$ \\
\hline Calverley et $\mathrm{a}^{32}$ & 1,022 & 12 & 64 & $\begin{array}{l}0.99 \mathrm{~L} \\
(36 \%)\end{array}$ & 39 & $\begin{array}{l}\text { BFC, } 320 / 9 \text { B, } 400 \\
\text { F, } 9 \text { PLB }\end{array}$ & Turbuhaler & $\begin{array}{l}\text { Time to first AECOPD } \\
\text { Change in FEV }\end{array}$ \\
\hline Tashkin et $\mathrm{al}^{34}$ & I,704 & 6 & 63 & $\begin{array}{l}\text { I L } \\
(40 \%)\end{array}$ & 40 & $\begin{array}{l}\text { BFC, } 320 / 9 \text { BFC, } \\
\text { 160/9 B, } 320+F \\
9 \mathrm{~B}, 320 \mathrm{~F}, 9 \text { PLB }\end{array}$ & pMDI & $\begin{array}{l}\text { Predose } F E V_{1} \\
\text { I h postdose } F E V_{1}\end{array}$ \\
\hline Rennard et $\mathrm{al}^{33}$ & 1,964 & 12 & 63 & $\begin{array}{l}\text { I L } \\
(39 \%)\end{array}$ & 40 & $\begin{array}{l}\text { BFC, } 320 / 9 \text { BFC, } \\
\text { I60/9 F, } 9 \text { PLB }\end{array}$ & pMDI & $\begin{array}{l}\text { Predose } F E V_{1} \\
\text { I h postdose } F E V_{1}\end{array}$ \\
\hline
\end{tabular}

Abbreviations: pMDI, pressurized metered dose inhaler; BFC, combination of budesonide and formoterol; B, budesonide; F, formoterol; PLB, placebo; FEV , forced expiratory volume in I second; AECOPD, acute exacerbation of COPD.

$\mathrm{FEV}_{1}$ significantly compared with $\mathrm{F}$ and PLB, whereas BFC (160/9 $\mu \mathrm{g}$ bid) only increased predose $\mathrm{FEV}_{1}$ significantly compared with PLB but not F. Interestingly, on the day of randomization, $\mathrm{BFC}$ increased $\mathrm{FEV}_{1}$ by $15 \%-18 \%$ and by $18 \%-20 \%$ at 5 minutes after the dose administration in Tashkin and Rennard studies, respectively. ${ }^{32,33}$ Similarly, at the end of the treatment, BFC resulted in $22 \%$ improvement in $\mathrm{FEV}_{1}$ at 5 minutes postadministration of the study medication. ${ }^{32}$ One-hour postdose inspiratory capacity (IC) increased significantly with BFC (both dosage strength) compared with F, PLB $(P<0.001),{ }^{32,33}$ and $\mathrm{B} .{ }^{33}$ Morning and evening PEF also significantly improved with $\mathrm{BFC}$ (both dosage strengths) compared with B, F, and PLB $(P<0.05) .{ }^{33}$ Thus, BFC, particularly at the higher dose $(320 / 9 \mu \mathrm{g}$ bid) improves various indices of lung function compared with B, F, or PLB alone (Figures 1A and B).

\section{Exercise capacity}

No published studies are available to describe the effects of $\mathrm{BFC}$ on exercise capacity in COPD. However, in an abstract, Worth et $\mathrm{al}^{36}$ reported the effects of BFC (320/9 $\mu \mathrm{g}$ bid) vs $\mathrm{F}$ ( $9 \mu \mathrm{g}$ bid) and PLB in a randomized, double-blind, placebo-controlled, crossover ( three 1-week treatment and 1-2 week wash-out periods) study in patients with COPD and increased functional residual capacity of $\geq 120 \%$. In this study, 111 patients were randomized and 91 completed the study. Study subjects were very similar to COPD patients enrolled in the 4 previously described pivotal studies. At 1 -hour postdose, exercise endurance time at constant work exercise test (75\% of peak work capacity) was significantly longer with BFC (517 seconds) compared with F (448 seconds; mean difference, 68.9 seconds; $P=0.0015)$ and PLB (412 seconds; mean difference, 105 seconds; $P<0.0001$ ). At 6-hour postdose, the exercise endurance time remained significantly longer (although less robust) with BFC compared with $\mathrm{F}$ (mean difference, 42.4 seconds; $P<0.05$ ) and PLB (mean difference, 62 seconds; $P=0.0025)$. At 1 -hour postdose iso-time IC (at 2 minutes into exercise) was significantly higher in BFC compared with PLB $(21 \% ; P<0.001)$ and showing a trend compared with $\mathrm{F}(6 \% ; P=0.063)$. In contrast, 6-hour postdose iso-time IC (at 2 minutes into exercise) was significantly higher in BFC compared with PLB $(8 \%$; $P<0.02)$ and $\mathrm{F}(7 \% ; P<0.05) .{ }^{36}$

\section{COPD exacerbations}

ICS alone or in combination with LABA reduce exacerbations of COPD. In a meta-analysis of 6 trials which evaluated the long-term effects ( $\geq 6$ months) of ICS in stable COPD, ICS reduced rates of exacerbation by nearly one-third relative to PLB (relative risk, 0.70; 95\% CI, 0.58-0.84). ${ }^{37}$ The 4 pivotal studies of BFC evaluated the impact of long-term treatments with BFC on exacerbations. It is important to mention that the definition of COPD exacerbation and the patient population enrolled in these studies were not uniform, and these facts have to be taken in consideration when analyzing the results.

In a12-month study of patients with moderate-to-severe COPD, Szafranski et $\mathrm{al}^{30}$ compared the effects of BFC (320/9 $\mu \mathrm{g}$ bid), B (400 $\mu \mathrm{g}$ bid), F (9 $\mu \mathrm{g}$ bid), or PLB. BFC significantly reduced the number of severe exacerbations by $11 \%$ and $23 \%$, and $24 \%$ compared with B, F, and PLB, respectively ( $P$ values are $0.385,0.043$, and 0.035 , respectively). Further, BFC compared with PLB significantly reduced the number of oral steroid courses used in association with an exacerbation $(31 \% ; P=0.027) .{ }^{30}$

Calverley et $\mathrm{al}^{31}$ studied patients with COPD (GOLD stage 3 or 4) with history of exacerbations requiring a course of oral corticosteroids and/or antibiotics 2-12 months prior to 
the first clinic visit. BFC prolonged time to first exacerbation requiring antibiotics and/or oral corticosteroids and/or hospitalization compared with all other treatments. The risk of having an exacerbation with BFC was reduced by $22.7 \%$, $29.5 \%$, and $28.5 \%$ compared with B, F, and PLB, respectively $(P=0.006$ vs $\mathrm{PLB}) .{ }^{31}$ The exacerbation rate with $\mathrm{BFC}$ was reduced compared with PLB (23.6\%) and F (25.5\%) but not with B alone (13.6\%). Neither B nor F affected either measures of exacerbation compared with PLB. Furthermore, BFC prolonged the time to first course of oral corticosteroids as well as the rate of oral corticosteroid courses compared with B, F, and PLB, respectively. ${ }^{31}$

Tashkin et $\mathrm{al}^{33}$ evaluated the effects of twice-daily inhalations of BFC (pMDI, 320/9 and 160/9 $\mu \mathrm{g}$ ), B (pMDI, $320 \mu \mathrm{g})$ plus F DPI $(9 \mu \mathrm{g}), \mathrm{B}(\mathrm{pMDI}, 320 \mu \mathrm{g}), \mathrm{F}$ (DPI, $9 \mu \mathrm{g}$ ), or PLB. The number of exacerbations (requiring oral corticosteroids and/or hospitalization) per patient-treatment year was numerically lower (approximately 20\%-25\%), but did not reach the predetermined statistical significance level ( $P \geq 0.060)$. This result was driven by the category of COPD exacerbations requiring treatment with oral corticosteroids. ${ }^{33}$

Rennard et al $^{32}$ compared the effects of twice-daily inhalations of BFC (pMDI, 320/9 $\mu \mathrm{g}$ ), BFC (pMDI, $160 / 9 \mu \mathrm{g}), \mathrm{F}$ (DPI, $9 \mu \mathrm{g}$ ), or PLB on exacerbations in patients with moderate to very severe COPD. BFC (both $320 / 9$ and $160 / 9 \mu \mathrm{g}$ dosage strengths) significantly prolonged time to first exacerbation compared with PLB $(P$ $\leq 0.004)$. BFC (320/9 $\mu \mathrm{g}$ bid) also significantly prolonged time to first exacerbation compared with $\mathrm{F}(P=0.026)$. In addition, significant reductions in the overall number of exacerbations per patient-treatment year were observed with BFC (both 320/9 and 160/9 $\mu \mathrm{g}$ dosage strengths) vs PLB (37\% and 41\%, respectively; $P<0.001)$ and $\mathrm{F}(25 \%$ and $29 \%$, respectively; $P \leq 0.004)$. These reductions were driven by exacerbations treated with oral corticosteroids, the rate of which was reduced with BFC and PLB, and $\mathrm{F}^{32}$

The reduction in COPD exacerbation rates observed with both BFC dosage strengths beyond the reduction achieved with formoterol alone further demonstrates the important contribution of budesonide to the combination product (Figure 1C). As shown in Figure 1C, the exacerbation rates were different between the 2 earlier studies (Szafranski et $\mathrm{al}^{30}$ and Calverley et al $)^{31}$ when compared with the 2 recent studies (Tashkin et $\mathrm{al}^{33}$ and Rennard et al) ${ }^{32}$. Although one cannot be sure about the reason for this difference, gradual advancement in therapy in last years and more stringent exclusion criteria may have changed the study populations.
A likely reason for lack of statistically significant reduction in acute exacerbation of COPD in Tashkin study may relate to the shorter duration of this study.

\section{Patient reported outcomes}

There have been only few studies that investigated the effects of BFC on patient reported outcomes. Most of these studies did measure quality of life using the Saint Georges Respiratory Questionnaire (SGRQ). In the Tashkin study, BFC improved SGRQ total scores compared with the B, $\mathrm{F}$, and PLB groups $(P \leq 0.05)$. These improvements were clinically meaningful (ie, reduction from baseline of $\geq 4$ points) for both BFC dosage strengths compared with the baseline values at all assessed time points. The percentage of patients in the BFC 320/9 $\mu \mathrm{g}$ and $160 / 9 \mu \mathrm{g}$ groups that demonstrated a clinically meaningful decrease (ie, improvement) in SGRQ total score from baseline to the end of the treatment compared with patients in the PLB group was significant, $45.5 \%$ and $45.4 \%$ as opposed to $35 \%(P<0.018)$. Calverley et $\mathrm{al}^{32}$ reported maintained quality of life with BFC compared with B, F, and PLB. Szafranski et $\mathrm{al}^{30}$ reported significant improvement in SGRQ total score with BFC compared with PLB (mean difference, 3.9; $P=0.009$ ). In Rennard's study, ${ }^{32}$ the improvement in SGRQ score with BFC (320/9 $\mu \mathrm{g}$ bid) compared with PLB and F was statistically significant but the difference did not reach clinically meaningful level (4-unit reduction).

In the study by Tashkin, ${ }^{33}$ patients kept a daily diary of the cough scores and a reduction was seen in the patients on BFC as opposed to the other study groups. BFC also improved dyspnea score (breathlessness diary) significantly compared with $\mathrm{B}, \mathrm{F}$, and PLB $(P \leq 0.044) .{ }^{33}$ Furthermore, rescue medication use was significantly decreased and rescue medication-free days were significantly increased with the use of BFC compared with $\mathrm{B}$ and PLB $(P<0.001) .{ }^{33}$ BFC significantly reduced the use of rescue medication by 0.8 inhalations per day compared with both B and PLB (both $P<0.001$ ), and by 0.3 inhalations per day compared with $\mathrm{F}(P<0.05) .{ }^{31}$ The percentage of awakening-free nights is another measure reported by the studies evaluating effects of BFC. BFC improved the nighttime awakenings score compared with PLB - the patients on BFC had a mean changes from run-in to the end of the treatment in the night-time awakening score of 0.16 $(P<0.004)$ compared with the patients on PLB. ${ }^{31}$ Tashkin et $\mathrm{al}^{33}$ reported improved sleep score and percentage of awakening-free nights in the patients using BFC compared with PLB $(P \leq 0.029)$. 

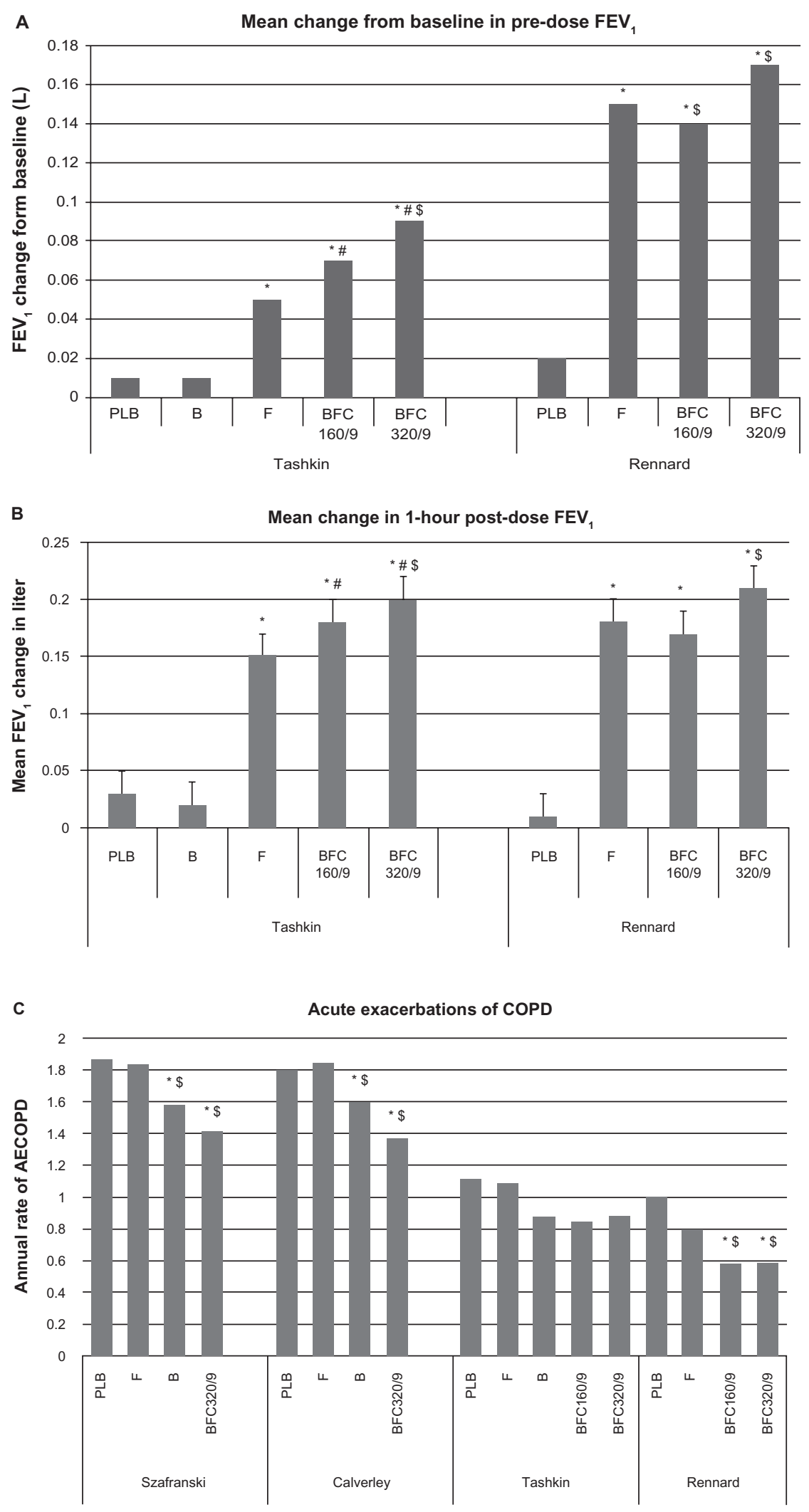

Figure I A-C shows the change in lung function and annual AECOPD rate in pivotal studies of BFC. A) shows the change in predose FEV , from baseline in different arms of Taskin et $\mathrm{al}^{34}$ and Rennard et $\mathrm{a}^{33}$ studies. B) shows the change in postdose $\mathrm{FEV}$, from baseline in different arms of Taskin et al ${ }^{34}$ and $\mathrm{Rennard}$ et $\mathrm{a}^{33}$ studies. $\mathbf{C}$ ) shows the annual rate of acute exacerbations of COPD (requiring systemic steroid or hospitalization) in 4 pivotal studies of BFC.

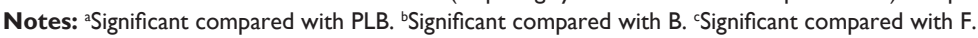

Abbreviations: BFC, combination of budesonide and formoterol; B, budesonide; F, formoterol; PLB, placebo; FEV obstructive pulmonary disease; AECOPD, acute exacerbation of COPD. 
Thus, in conclusion, the use of BFC may significantly improve patient reported outcomes including dyspnea, quality of life, use of rescue inhaler, and symptom-free nights.

\section{Safety end points of budesonide/ formoterol combination}

The 4 large pivotal studies of BFC described earlier evaluated the safety of the study medications. These studies did not detected clinically meaningful differences among various study arms with adverse events (AEs) mostly judged as mildto-moderate intensity by the study physicians.

Szafranski et $\mathrm{al}^{30}$ reported similar AE profiles in each group with proportionally more patients reporting COPD events in the PLB group than in the active treatment groups $(17 \%, 13 \%, 19 \%$, and $26 \%$ in the BFC, B, F, and PLB groups, respectively). The percent of patients with serious adverse events (SAEs) were similar (20\% and 22\% for PLB and BFC arms, respectively). Also similar SAEs per 1,000 treatment days were observed between the groups ( 0.9 and 0.8 for PLB and BFC arms, respectively). Further, no clinically important inter-group OR differences were identified for ECG measurements. Similarly, Calverley et al ${ }^{31}$ did not detect major differences in safety profile in the study, AE profile, SAE numbers, and mortality among various study arms. Tashkin et $\mathrm{a}^{33}$ and Rennard et a ${ }^{32}$ reported higher incidence of nasopharyngitis (7.3\% and $4.9 \%$ ), oral candidiasis ( $6 \%$ and $1.8 \%$ ), bronchitis (5.4\% and $3.5 \%)$, sinusists (3.5\% and $1.8 \%$ ), and viral upper respiratory tract infection (3.5\% and 2.7\%) in BFC (320/9 bid) and PLB groups, respectively. ${ }^{38} \mathrm{AE}$-related withdrawals ranged between $6.9 \%$ and $11.3 \%$ in patients receiving BFC (320/9 bid). ${ }^{32,33}$ No significant difference was detected in incidence of pneumonia between BFC and PLB arms.

\section{Cost effectiveness budesonide/ formoterol combination}

Halpin $^{39}$ reported on cost effective analysis of BFC in patients with asthma and COPD. The analysis used data from 2 studies. Data from Calverlay et al ${ }^{31} 12$-month randomized study, indicated that greater cost of BFC was offset by lower exacerbations and hospitalization. In a modeling study using data from Szafranski's 12-month study, Dal Negro et a ${ }^{40}$ reported that $\mathrm{BFC}$ gave a better outcome at lower cost compared with monotherapy.

\section{Comparison of BFC with fluticasone/ salmetero combination}

The 2 available combination therapies including BFC (Symbicort $^{\mathrm{T}}$, Astrazeneca) and fluticasone/salmeterol combination (Advair $^{\text {TwM }}$, GSK, UK) were compared in few small studies. Partridge et $\mathrm{al}^{41}$ studied 442 subjects with COPD in a randomized crossover study with 1-week exposure to each of the study medications. BFC showed earlier onset of action in regard to lung function with greater improvements in total morning activity scores. However, the improvement in the symptom scores (within 15 minutes) postmedications were similar between the 2 combinations. ${ }^{41}$ Lindberg et al ${ }^{42}$ conducted a single dose study comparing BFC with fluticasone/salmeterol combination. The BFC improved FEV 1 at 5 minutes more than fluticasone/salmeterol combination but the maximum response was not different between the 2 combinations. ${ }^{42}$

\section{Questions and future development}

Randomized clinical trials clearly show significant effect of combination therapy of inhaled steroid and LABA on various COPD-related clinical outcomes. However, a major area of research is identification of subgroups of COPD subjects that will benefit the most from the combination therapy and those that may have the most AEs. As formoterol is a fastacting bronchodilator, BFC may have potential for use or abuse as a rescue medication. BFC is allowed to be used as rescue ( 1 extra dose) in Europe for asthma but not approved by US FDA..$^{43,44}$ Use of BFC as rescue in COPD is not clearly established. Further studies to find out how frequently BFC is used as rescue and the safety of such use are needed. This data is particularly important as the new US FDA warning about use of LABA in asthma and the black box warning for the available products in the market. ${ }^{45}$

\section{Summary}

Four large randomized trials clearly indicate that in patients with moderate or severe COPD who have a history of a COPD exacerbation, BFC improves various COPD-related outcomes including lung function, health-related quality of life, and reduces the incidence of exacerbations compared with the individual components alone or placebo. Furthermore, data from 1-year trials demonstrate that the long-term use of this combination is safe. Future studies need to evaluate the effect of this combination therapy on airway inflammatory indices and in patients with milder disease.

\section{Disclosures}

Amir Sharafkhaneh, is on the speakers' bureau of GSK, Boehringer Ingelheim, Pfizer, AstraZeneca and DEY. Nicola Hanania, is on the speakers' bureau of GSK, Boehringer Ingelheim, Pfizer, AstraZeneca and DEY. 


\section{References}

1. Celli BR, MacNee W. Standards for the diagnosis and treatment of patients with COPD: a summary of the ATS/ERS position paper. Eur Respir J. 2004;23(6):932-946.

2. Mannino DM, Homa DM, Akinbami LJ, Ford ES, Redd SC. Chronic obstructive pulmonary disease surveillance - United States, 1971-2000. MMWR Surveill Summ. 2002;51(6):1-16.

3. Mannino DM. COPD*: epidemiology, prevalence, morbidity and mortality, and disease heterogeneity. Chest. 2002;121:121S-126S.

4. U.S. Department of Health and Human Services. National Institutes of Health. National Heart Lung and Blood Institute. Morbidity and Mortality: 2007 Chartbook on Cardiovascular, Lung and Blood Diseases. 2007. Available from: http://www.nhlbi.nih.gov/resources/ docs/07-chtbk.pdf

5. Rabe KF, Hurd S, Anzueto A, et al. Global strategy for the diagnosis, management, and prevention of COPD - 2006 Update. Am J Respir Crit Care Med. 2007;200703-2456SO.

6. Cooper CB. The connection between chronic obstructive pulmonary disease symptoms and hyperinflation and its impact on exercise and function. Am J Med. 2006;119(10 Suppl 1):21-31.

7. Hogg JC, Chu F, Utokaparch S, et al. The nature of small-airway obstruction in chronic obstructive pulmonary disease. $N$ Engl J Med. 2004; 350(26):2645-2653.

8. Hogg JC, Macklem PT, Thurlbeck WM. Site and nature of airway obstruction in chronic obstructive lung disease. $N$ Engl J Med. 1968; 278(25): 1355-1360.

9. Hogg JC, Chu FS, Tan WC, et al. Survival after lung volume reduction in chronic obstructive pulmonary disease: insights from small airway pathology. Am J Respir Crit Care Med. 2007;176(5): 454-459.

10. Anthonisen NR, Connett JE, Kiley JP, et al. Effects of smoking intervention and the use of an inhaled anticholinergic bronchodilator on the rate of decline of FEV1. The Lung Health Study. JAMA. 1994;272(19):1497-1505.

11. Lemoine H, Overlack C, Kohl A, Worth H, Reinhardt D. Formoterol, fenoterol, and salbutamol as partial agonists for relaxation of maximally contracted guinea pig tracheae: comparison of relaxation with receptor binding. Lung. 1992;170(3):163-180.

12. Lotvall J. Pharmacological similarities and differences between beta2agonists. Respir Med. 2001;95 Suppl B:S7-S11.

13. Hanania NA, Moore RH, Zimmerman JL, et al. The role of intrinsic efficacy in determining response to a beta2-agonist in acute severe asthma. Respir Med. 2007;101(5):1007-1014.

14. Anderson GP. Formoterol: pharmacology, molecular basis of agonism, and mechanism of long duration of a highly potent and selective beta 2-adrenoceptor agonist bronchodilator. Life Sci. 1993;52(26): 2145-2160

15. van der Woude HJ, Aalbers R. Long-acting beta2-agonists: comparative pharmacology and clinical outcomes. Am J Respir Med. 2002;1(1): 55-74.

16. Lecaillon JB, Kaiser G, Palmisano M, Morgan J, Della CG. Pharmacokinetics and tolerability of formoterol in healthy volunteers after a single high dose of Foradil dry powder inhalation via Aerolizer. Eur $J$ Clin Pharmacol. 1999;55(2):131-138.

17. Barnes PJ. Molecular mechanisms of glucocorticoid action in asthma. Pulm Pharmacol Ther. 1997;10(1):3-19.

18. Barnes PJ, Adcock I. Anti-inflammatory actions of steroids: molecular mechanisms. Trends Pharmacol Sci. 1993;14(12):436-441.

19. Ryrfeldt A, Persson G, Nilsson E. Pulmonary disposition of the potent glucocorticoid budesonide, evaluated in an isolated perfused rat lung model. Biochem Pharmacol. 1989;38(1):17-22.

20. Finney PA, Donnelly LE, Belvisi MG, et al. Chronic systemic administration of salmeterol to rats promotes pulmonary beta(2)-adrenoceptor desensitization and down-regulation of G(s alpha). Br J Pharmacol. 2001;132(6):1261-1270.

21. Mak JC, Nishikawa M, Barnes PJ. Glucocorticosteroids increase beta 2-adrenergic receptor transcription in human lung. Am J Physiol. 1995; 268(1 Pt 1):L41-L46.
22. Collins S, Caron MG, Lefkowitz RJ. Beta-adrenergic receptors in hamster smooth muscle cells are transcriptionally regulated by glucocorticoids. J Biol Chem. 1988;263(19):9067-9070.

23. Tan KS, Grove A, McLean A, Gnosspelius Y, Hall IP, Lipworth BJ. Systemic corticosteriod rapidly reverses bronchodilator subsensitivity induced by formoterol in asthmatic patients. Am J Respir Crit Care Med. 1997;156(1):28-35.

24. Barnes PJ. Scientific rationale for inhaled combination therapy with long-acting beta2-agonists and corticosteroids. Eur Respir J. 2002;19(1):182-191.

25. Baraniuk JN, Ali M, Brody D, et al. Glucocorticoids induce beta2adrenergic receptor function in human nasal mucosa. Am J Respir Crit Care Med. 1997;155(2):704-710.

26. Mak JC, Nishikawa M, Shirasaki H, Miyayasu K, Barnes PJ. Protective effects of a glucocorticoid on downregulation of pulmonary beta 2 -adrenergic receptors in vivo. J Clin Invest. 1995;96(1): 99-106.

27. Eickelberg O, Roth M, Lorx R, et al. Ligand-independent activation of the glucocorticoid receptor by beta2-adrenergic receptor agonists in primary human lung fibroblasts and vascular smooth muscle cells. J Biol Chem. 1999;274(2):1005-1010.

28. Roth M, Johnson PR, Rudiger JJ, et al. Interaction between glucocorticoids and beta 2 agonists on bronchial airway smooth muscle cells through synchronised cellular signalling. Lancet. 2002;360(9342): 1293-1299.

29. Spoelstra FM, Postma DS, Hovenga H, Noordhoek JA, Kauffman HF. Additive anti-inflammatory effect of formoterol and budesonide on human lung fibroblasts. Thorax. 2002;57(3):237-241.

30. Szafranski W, Cukier A, Ramirez A, et al. Efficacy and safety of budesonide/formoterol in the management of chronic obstructive pulmonary disease. Eur Respir J. 2003;21(1):74-81.

31. Calverley PM, Boonsawat W, Cseke Z, Zhong N, Peterson S, Olsson H. Maintenance therapy with budesonide and formoterol in chronicobstructive pulmonary disease. Eur Respir J. 2003;22(6):912-919.

32. Rennard SI, Tashkin DP, McElhattan J, et al. Efficacy and tolerability of budesonide/formoterol in one hydrofluoroalkane pressurized metereddose inhaler in patients with chronic obstructive pulmonary disease: results from a 1-year randomized controlled clinical trial. Drugs. 2009; 69(5):549-565.

33. Tashkin DP, Rennard SI, Martin P, et al. Efficacy and safety of budesonide and formoterol in one pressurized metered-dose inhaler in patients with moderate to very severe chronic obstructive pulmonary disease: results of a 6-month randomized clinical trial. Drugs. 2008; 68(14):1975-2000.

34. Morice AH, Peterson S, Beckman O, Osmanliev D. Therapeutic comparison of a new budesonide/formoterol pMDI with budesonide pMDI and budesonide/formoterol DPI in asthma. Int J Clin Pract. 2007; 61(11):1874-1883.

35. Morice AH, Hochmuth L, Ekelund J, Thoren A, Puterman AS. Comparable long-term safety and efficacy of a novel budesonide/formoterol pressurized metered-dose inhaler versus budesonide/formoterol Turbuhaler in adolescents and adults with asthma. Pulm Pharmacol Ther 2008;21(1):32-39.

36. Worth H, Foerster K, Peterson S, Nihlen U, Magnussen H. Budesonide/ formoterol improves exercise tolerance compared with placebo and formoterol in COPD patients. Eur Respir J. 2009;30:12s.

37. Alsaeedi A, Sin DD, McAlister FA. The effects of inhaled corticosteroids in chronic obstructive pulmonary disease: a systematic review of randomized placebo-controlled trials. Am J Med. 2002; 113(1):59-65.

38. Lyseng-Williamson KA. Budesonide/formoterol pressurized metereddose inhaler: in chronic obstructive pulmonary disease. Drugs. 2009; 69(11):1459-1470.

39. Halpin DM. Symbicort: a pharmacoeconomic review. J Med Econ. 2008;11(2):345-362.

40. Dal Negro R. Optimizing economic outcomes in the management of COPD. Int J Chron Obstruct Pulmon Dis. 2008;3(1):1-10. 
41. Partridge MR, Schuermann W, Beckman O, Persson T, Polanowski T. Effect on lung function and morning activities of budesonide/formoterol versus salmeterol/fluticasone in patients with COPD. Ther Adv Respir Dis. 2009;3(4):1-11.

42. Lindberg A, Szalai Z, Pullerits T, Radeczky E. Fast onset of effect of budesonide/formoterol versus salmeterol/fluticasone and salbutamol in patients with chronic obstructive pulmonary disease and reversible airway obstruction. Respirology. 2007;12(5):732-739.

43. Vogelmeier C, D’Urzo A, Pauwels R, et al. Budesonide/formoterol maintenance and reliever therapy: an effective asthma treatment option? Eur Respir J. 2005;26(5):819-828.
44. Rabe KF, Atienza T, Magyar P, Larsson P, Jorup C, Lalloo UG. Effect of budesonide in combination with formoterol for reliever therapy in asthma exacerbations: a randomised controlled, double-blind study. Lancet. 2006;368(9537):744-753.

45. FDA Announces New Safety Controls for Long-Acting Beta Agonists, Medications Used to Treat Asthma. 2010.

\section{Publish your work in this journal}

The International Journal of COPD is an international, peer-reviewed journal of therapeutics and pharmacology focusing on concise rapid reporting of clinical studies and reviews in COPD. Special focus is given to the pathophysiological processes underlying the disease, intervention programs, patient focused education, and self management protocols.
Dovepress

This journal is indexed on PubMed Central, MedLine and CAS. The manuscript management system is completely online and includes a very quick and fair peer-review system, which is all easy to use. Visit http://www.dovepress.com/testimonials.php to read real quotes from published authors.

Submit your manuscript here: http://www.dovepress.com/international-journal-of-copd-journal 